\title{
Biobanking across the phenome - at the center of chronic disease research
}

\author{
Medea Imboden ${ }^{1,2^{*}}$ and Nicole M Probst-Hensch ${ }^{1,2}$
}

\begin{abstract}
Background: Recognized public health relevant risk factors such as obesity, physical inactivity, smoking or air pollution are common to many non-communicable diseases (NCDs). NCDs cluster and co-morbidities increase in parallel to age. Pleiotropic genes and genetic variants have been identified by genome-wide association studies (GWAS) linking NCD entities hitherto thought to be distant in etiology. These different lines of evidence suggest that NCD disease mechanisms are in part shared.

Discussion: Identification of common exogenous and endogenous risk patterns may promote efficient prevention, an urgent need in the light of the global NCD epidemic. The prerequisite to investigate causal risk patterns including biologic, genetic and environmental factors across different NCDs are well characterized cohorts with associated biobanks. Prospectively collected data and biospecimen from subjects of various age, sociodemographic, and cultural groups, both healthy and affected by one or more NCD, are essential for exploring biologic

mechanisms and susceptibilities interlinking different environmental and lifestyle exposures, co-morbidities, as well as cellular senescence and aging. A paradigm shift in the research activities can currently be observed, moving from focused investigations on the effect of a single risk factor on an isolated health outcome to a more comprehensive assessment of risk patterns and a broader phenome approach. Though important methodological and analytical challenges need to be resolved, the ongoing international efforts to establish large-scale population-based biobank cohorts are a critical basis for moving NCD disease etiology forward.
\end{abstract}

Summary: Future epidemiologic and public health research should aim at sustaining a comprehensive systems view on health and disease. The political and public discussions about the utilitarian aspect of investing in and contributing to cohort and biobank research are essential and are indirectly linked to the achievement of public health programs effectively addressing the global NCD epidemic.

Keywords: Comorbidities, Cohort, Genome wide association study, Non-communicable disease, Phenome, Public health, Risk factors

\section{Background}

The aim of the present report is to address the importance of studying non-communicable diseases (NCDs) and their relationship to aging in a systems approach. Understanding the complexity and interrelation of risk factors and disease networks requires the biologic sample collection, detailed and comprehensive phenotyping, and broad risk factor data. We present the international progress made in establishing large population-based biobank cohorts with the explicit aim to investigate non-communicable disease (NCD) etiology longitudinally. We point to the current

\footnotetext{
* Correspondence: medea.imboden@unibas.ch

${ }^{1}$ Swiss Tropical and Public Health Institute, Basel, Switzerland

2University of Basel, Basel, Switzerland
}

\section{Biomed Central}

inadequacy and the critical need to invest substantial research funding into NCD research in low and middle income countries in which the rise of NCDs converges with the high prevalence of infectious diseases. We discuss the relevance of studying pathophysiologic mechanisms linking different age-related NCDs and the aging process. We also highlight recent examples of phenome approaches. Finally, we point out striking pleiotropic findings of NCD phenotypic traits and genome-wide associations (GWAS) which clearly signpost an on-going paradigm shift in NCD research and underscore the potential of agnostic, complex data, systemic and multi-levelled methodologies leading to new understanding of chronic disease etiology. 


\section{International trend for prospective large-sized biobank cohorts}

NCDs convey more than $50 \%$ of the global burden of disease and are challenging the health of populations worldwide. In high income countries (HICs), the epidemic of NCDs has been recognizably the major public health challenge over the last decades [1]. For this reason several HICs have increased their research efforts and invested substantial funding in extremely large population-based prospective cohort studies (with samples sizes over 200' 000). These mega-cohorts (Table 1; see also www.p3g.org) apply detailed phenotype descriptions over time, exhaustive temporal assessment of personal and environmental information and include high quality biologic sample collections for future genetic and functional analyses [2]. Prospective biobanking represents a powerful tool for establishing causal relationships as the time-order of sampling and of phenotyping is generally clear. Both hypothesis-driven as well as agnostic research can be conducted. Biologic samples in research can be used to test genetic determinants (e.g. genetic variants of $\mathrm{N}$-Acetyltransferases, NAT1 and NAT2) potentially mediating susceptibility (e.g. increased cancer risk), to discover or validate biomarkers as land marks of mechanisms (e.g. acetylation of aromatic and heterocyclic amines), or to sense and estimate individual environmental exposures (e.g. variable toxicity of carcinogens). Additional applications are expected to increase in the future. General good practices for biobanking in research have been defined (e.g. www. ieaweb.org for epidemiologic settings). An increasing need for biologic samples has therefore been the driving force to establish biobank collections in various clinical and observational settings [3]. A well-known example is the UK biobank, collecting blood, saliva and urine of more than 500'000 participants. Questionnaire and measurement data were collected at baseline and follow-up examinations are performed in subsets of the cohort [4]. There are also efforts of similar dimension in low and middle income countries (LMIC) such as the Chinese Biobank Study [Kadoorie Study of Chronic Disease in China (KSCDC)]. This project is a blood-based health database aiming at collecting genetic, environmental and lifestyle data on 510 '000 adults aged 30-79 years to understand the causes, risk factors, pathogenesis, prevalence patterns and trends of major infectious and NCDs [5]. The establishment, maintenance and repeated collection of participant data require a substantial long-term investment of research funds. Critical voices point to the tremendous costs and to the methodological challenges to keep bias low over a long follow-up time in a multi-centric study design. But the scientific utility of such large longitudinal datasets is undisputed [6,7]. Understanding the genetic, molecular and mechanistic background of interdependence between NCDs, comorbidities and risk factors during the aging process is a research priority for public health. Sufficiently powered cohorts and biobanks with broad, yet refined characterization of participants for risk factors and health phenotypes are a conditio sine qua non to achieve this goal.

\section{Discussion}

\section{Biobank cohorts and chronic disease research in low and middle income countries (LMIC)}

Research on NCDs almost exclusively relies on cohort data and associated biological samples collected in HICs. The recent update of global burden of disease estimates marks a shift from communicable towards non-communicable diseases and from life years lost due to premature death to increased number of years lived with chronic diseases and disabilities in LMICs $[1,8]$. Though regionally heterogeneous, the LMICs show a persistently high proportion of infectious diseases in addition to a recent increase in prevalence of NCDs such as ischemic heart disease, stroke and diabetes. This observed convergence of NCDs and communicable diseases causes a dual burden of disease [9] for which most LMICs not only lack adequate health system resources, but also research funds to address the regional and local public health challenges [10]. Though causal relationships of NCD etiology and preventive measures identified in population-based biobank cohort studies in HICs will most likely inform public health decisions in LMICs, it is obvious that repeating studies of established NCD risk factors in LMICs will be necessary for proper estimation of their contribution to the disease burden [11]. Much can be learned about effect modifiers and risk factors by paralleled establishment of biobank cohorts in different settings. From human genome variation studies we already know that many African populations harbour a larger degree of genetic variation [12]. Several examples of high quality cohort study efforts in LMIC have been undertaken [7] (Table 1). For example, the prevalence of healthy lifestyle in patients with cardiovascular disease $(n=7519)$ was investigated in the PURE study, a large-scale epidemiological study that recruited $>140,000$ individuals residing in in 17 low-, middle-, and highincome countries around the world, and revealed strong correlation of decreasing levels of healthy lifestyle with decreasing country income level [13]. The Guangzhou Biobank Cohort Study [14], combining the use of biomarkers and questionnaire data for investigation of NCDs health system use as well as NCDs etiology, is another excellent example of a regional population-based cohort study in a country transiting fast from low to high income settings, albeit with large social discrepancies. Such large scale biobank cohort studies in LMICs face numerous challenges including funding, political, cultural and religious issues, but they are imminently important to collect data and monitor the dynamics of changes in 


\section{Table 1 Selection of ongoing mega-cohort studies in adults}

\begin{tabular}{|c|c|c|c|c|c|c|c|}
\hline Web site & Cohort study & Country & Country size & Focus & Sample size & Baseline & Biologic samples \\
\hline- & CONOR/HUNT & Norway & 4,9 Mio & Common disease etiology & $185^{\prime} 000$ & 1994-1995 & Blood \\
\hline http://www.millionwomenstudy.org/ & Million women study & United Kingdom & 62,3 Mio & Women's health & 1'300'000 & $1996-2001$ & $\begin{array}{l}\text { Blood, saliva, } \\
\text { in a sub-sample }\end{array}$ \\
\hline http://epic.iarc.fr/ & EPIC & Europe & 738,2 Mio & $\begin{array}{l}\text { Nutrition, life style and cancer other } \\
\text { diseases }\end{array}$ & $520^{\prime} 000$ & 1997 & Blood \\
\hline- & $\begin{array}{l}\text { Mexico city prospective } \\
\text { study }\end{array}$ & Mexico & 117,4 Mio & $\begin{array}{l}\text { Major determinants of morbidity } \\
\text { and premature mortality }\end{array}$ & $150^{\prime} 000$ & 1998-2004 & Blood \\
\hline http://www.decode.com/research/ & deCODE & Iceland & $0.4 \mathrm{Mio}$ & Research company & $200^{\prime} 000$ & 2000 & Various \\
\hline http://www.milleniumcohort.org/ & Millennium & USA & 313,3 Mio & US military family cohort & $150^{\prime} 000$ & 2001 & Not specified \\
\hline http://www.geenivaramu.ee/en/ & Estonian biobank & Estonia & $1.3 \mathrm{Mio}$ & Biologic resource & $50^{\prime} 000$ & 2002 & Blood \\
\hline $\begin{array}{l}\text { http://www.birmingham.ac.uk/research/activity/ } \\
\text { mds/projects/HaPS/PHEB/Guangzhou/index.aspx }\end{array}$ & $\begin{array}{l}\text { Guanghzou Biobank } \\
\text { Cohort study }\end{array}$ & China & 1339,7 Mio & $\begin{array}{l}\text { Genetic, lifestyle, occupational and } \\
\text { environmental factors, and life course } \\
\text { Causes of the common chronic } \\
\text { diseases }\end{array}$ & $40^{\prime} 000$ & 2003 & Blood, urine \\
\hline http://www.ckbiobank.org/ & China Kandoorie Biobank & China & 1339,7 Mio & $\begin{array}{l}\text { Chronic disease etiology, complex } \\
\text { interplay of lifestyle, environmental, } \\
\text { and genetic susceptibility }\end{array}$ & $500^{\prime} 000$ & 2004-2008 & Blood \\
\hline http://www.phri.ca/pure/index.html & PURE & Several countries & $3223,7 \mathrm{MiO}$ & $\begin{array}{l}\text { Maladaptation to urbanization and } \\
\text { cardiovascular health }\end{array}$ & $120^{\prime} 000$ & 2006 & Blood \\
\hline http://www.ukbiobank.ac.uk/ & UK biobank & United Kingdom & $62,3 \mathrm{Mio}$ & Common disease etiology & $500^{\prime} 000$ & $2007-2010$ & Blood, saliva, urine \\
\hline http://www.lifelines.net/ & LifeLines & The Netherlands & 16,8 Mio & $\begin{array}{l}\text { causes and prognosis of burden of } \\
\text { disease, co-determinants, rather } \\
\text { than comorbidity, family study }\end{array}$ & $165^{\prime} 000$ & 2007 & Blood, urine \\
\hline $\begin{array}{l}\text { https://www.etude-nutrinet-sante.fr/fr/ } \\
\text { common/login.aspx }\end{array}$ & Nutrinet Santé & France & 65,4 Mio & Nutrition and health & $500^{\prime} 000$ & 2009 & Blood, urine \\
\hline http://www.partnershipfortomorrow.ca/ & $\begin{array}{l}\text { The Canadian Partnership } \\
\text { for Tomorrow Project } \\
\text { (CPTP) }\end{array}$ & Canada & 34,4 Mio & Cancer and chronic disease etiology & $300^{\prime} 000$ & 2009 & Blood \\
\hline http://lifegene.ki.se/ & Life gene & Sweden & $9,4 \mathrm{Mio}$ & Nealth and lifestyle & $500^{\prime} 000$ & 2011 & Blood, urine \\
\hline http://www.constances.fr & CONSTANCES & France & 65,4 Mio & Biologic and research resource & $5000^{\prime} 000$ & 2011 & Blood \\
\hline http://www.nationale-kohorte.de/index_en.html & German national cohort & Germany & 81,8 Mio & Common disease etiology & $200 \prime 000$ & 2012 & Blood \\
\hline
\end{tabular}

Listed by date of baseline examination start. 
environmental, life style, societal and health parameters with the increasing trend of urbanization in these countries [7]. They also contribute importantly to increasing the global competitiveness of research in LMICs [15].

\section{Phenome approach towards disease networks}

In aiming to improve understanding of NCD etiology refined phenotyping of specific health outcomes is a necessity. Clinical disease diagnosis based research is known to be challenged by phenotypic heterogeneity. As an example, asthma, an intermittent chronic respiratory disease can be defined as a clinical diagnosis of asthma, but it is known that there are important differences in etiology and mechanisms depending on age of asthma onset or the presence of atopy and allergies. GWAS findings clearly revealed that the locus 17q21 determined childhood and not adult onset asthma [16,17]. Statistical clustering approaches applied to the multilayer disease characteristics of a large group of asthmatic patients identified four distinct asthma phenotype groups: active treated allergic childhood-onset asthma; active treated adult-onset asthma; inactive or mild untreated asthma differing by atopy status and age of asthma onset [18]. In general up to recently, genetic investigations of NCD determinants, especially in large-scale GWAS metaanalyses, reduced the phenotype studied to a clinical diagnostic entity, a fact that may contribute to the disappointingly low predictive power of common genetic disease variants identified to date [19-21]. The importance of precise phenotyping for identifying the genetic contribution to common disease has been stressed since the time point of completion of the human genome project [22]. Clearly this challenges meta-analyses of data from different medium-sized cohorts collected in non-harmonized ways. International efforts to develop harmonized phenotype definitions lead early on to the Human Phenome Project $[22,23]$. Since the initiative call phenome based databases were established (e.g. bipolar disorder phenome [24]; epilepsy phenome/genome project [25]; mouse phenome [26]; human pathology centered phenomes on cardiomyopathy [27], deafness [28], cardiac conduction characteristics [29], human skeletal phenome [30]). Phenotypes forming the basis of the phenome approaches can refer to any characteristic or trait measureable in an organism. It can be as diverse as a morphologic, biochemical, physiological, electrical, behavioral, epigenetic trait and these measures show a large inter-individual variability. Recently phenomebased approaches proofed their usefulness in identifying context-dependent clinical reference values for white blood cell counts [31]. Other recent phenome approaches applied semantic web technologies to scan electronic health records comprising clinical and biologic medical data for identifying genotype-phenotype associations [32,33]. The current applications of the phenome approaches illustrate well the broad definition of the "phenome" summarizing often a large collection of phenotypes. Refined phenome approaches must be expanded to the concept of disease networks [34,35], the Diseasome. According to a European population-based survey $25 \%$ of the respondents of age older than 14 years reported the presence of more than one chronic condition [36]. A systematic evidence review reported prevalence ranges of multi-morbidity in elderly of $55 \%$ to $98 \%$ [37]. The identification and clustering of human disease etiologic factors was undertaken in a bioinformatic driven data-mining approach using $\mathrm{MeSH}$ annotation of MEDLINE-referenced articles and the authors produced the etiome profile for 863 diseases (available at http://etiome.stanford.edu) [38]. New analytical approaches open novel exploratory avenues of investigation supporting the paradigm shift towards systematic, multilayered and more exhaustive phenotypic catalogs. Patient records from a 1.5 million large patient population were used to establish correlation links of 161 disorders with disease phenotypes allowing to estimate the genetic overlap within the disease network [39]. A comorbidity database, the human disease network, was established from the analysis of 30 Mio Medicare patient data linking diseases and comorbidities (available at http://hudine.neu.edu/) [40]. More recently, to better understand disease similarities independent research groups have explored the clustering of genome-phenome correlations on a large number of published phenotype - gene associations [41], or the type 2 diabetes genetic loci [42] or the major histocompatibility complex class II surface receptor, HLADRB1 [43]. These reports clearly proof the huge potential of bioinformatics-driven data-mining methodologies to shape the diseasome by classification of disease phenotypes and molecular diseases pathways. Thus such public health relevant research will continue to steadily improve our understanding of the phenotypic overlap of different NCDs and their link to aging processes. These system approaches to disease must furthermore be paralleled by systems approaches to understand risk factors. The concept of the phenome has thus been supplemented by the concept of the Exposome which measures environmental exposure as internal intermediate phenotypes of exposed organisms [44-46] using metabolomic and proteomic methods for quantification of molecular traits.

Accelerated aging processes as a link to NCD comorbidity Given that NCDs are chronic the proportion of comorbidities or secondary NCDs increase with age. Beyond this play of chance, NCD risk factors are known to accelerate the aging process of various organs. Smoking and obesity are among the most consistent factors showing adverse effects on all features of aging. For example, smoking, a potent risk factor for cardiovascular and respiratory NCDs has been suggested to promote cellular senescence of the 
lung [47], to impair the immune response [48] and increase skin aging [49]. Likewise obesity, a major risk factor for cardiovascular NCDs has been associated with age-related disease of the CNS [50]. Telomere shortening, a marker of the aging process, is inversely associated with several risk factors of diabetes and mitochondrial function in diabetic patients compared to healthy controls [51]. Telomere length was positively correlated with good glycemic/lipid control and negatively correlated with adiposity and insulin resistance [51,52]. Other NCD risk factors such as sun light or weight loss exhibit adverse effects on more restricted features of aging such as skin aging or osteoporosis (see Table 2 as illustrative example).

The natural history of aging is characterized by a diminished self-renewal capacity of the organism resulting in sclerodermatous changes of the skin, alopecia, osteoporosis, sarcopenia, muscle atrophy, generalized lipodystrophy, atherosclerosis, decreased elasticity of the vascular system, immunologic senescent changes such as decline in humoral immunity, T-cell functional dysregulation, innate and adaptive immune functions $[48,59,64,67]$. Characteristic land marks of aging are also neurologic senescent changes of the central, peripheral and autonomic nervous system including limited neuronal loss, glial proliferation in the cortex and an overall brain weight decrease, degradation of sensory performance, decline in proprioception and somatosensory information processing and also reduced reactivity of the sympathetic and the parasympathetic nervous activity $[68,69]$. It is likely that systemic approaches combining the focus on accelerated aging, NCDs, environmental and genetic risk factors will point to the underlying disease biology. Understanding how shared risk factors affect mechanisms common to NCDs and aging processes is important from a public health perspective to meet effective prevention programs.

\section{Lessons learned from genetics on NCD clustering: pleiotropic gene variants}

Despite ongoing debates about the limitation of GWAS findings from the predictive personalized medicine perspective, GWAS studies do not announce the end of complex disease genetics, but rather a promising first step. Completely novel genes expand our understanding of NCD pathology. A large number of GWAS loci have been consistently associated with one or multiple NCDs in independent populations (see Additional file 1; www. genome.gov/gwastudies). Evidence for pleiotropy of loci, genes and even specific SNPs suggests important mechanistic links between diseases and is of potential relevance to advance understanding the biology of NCD clusters, co-morbidities and aging processes. A recent meta-analysis of 372 GWAS on 105 unique age-related diseases revealed the clustering of genetic variants in ten significantly enriched chromosomal locations which contain genes involved in inflammation and cellular senescence [70]. Pleiotropy is defined as a genetic variant or a gene having an effect on multiple phenotypes. In Table 3, we present an overview of specific SNPs likely to be pleiotropic. They were consistently associated with different forms of cancer (i.e. rs401681, TERT, CLPTM1L, 5p15.33 - associated with lung, bladder, pancreatic cancer, melanoma and prostatespecific antigen levels) and of chronic inflammatory diseases (i.e. rs11209026, IL23R, 1p31.3 - associated with Crohn's disease, ulcerative colitis, ankylosing spondylitis and psoriasis; rs10488631, IRF5,TNPO3, 7q32.1 - associated with systemic lupus erythematosus, systemic sclerosis, rheumatoid arthritis and primary biliary cirrhosis; see Additional file 2 for detailed summary of pleiotropic SNPs). This observed non-random clustering of NCD-linked traits and specific pleiotropic SNPs can be used to identify biologic mechanisms shared by different NCDs. In a recent study a method was presented to evaluate the pleiotropy among GWAS-identified SNPs and genes for common complex disease and traits; it reported that $17 \%$ of the GWAS genes and 4\% of the GWAS SNPs showed evidence of pleiotropy [71]. Although pleiotropy had been suggested to be common to the genetic architecture of complex disease [72], only isolated cases of pleiotropy had been reported previously such as the links between $A P O E$ genotypes and dyslipidemia, coronary heart disease and Alzheimer's disease [73], and type 2 diabetes and prostate cancer (TCF2 genotypes) [74]. The genetic overlap between psoriasis, diabetes type 2 and Crohn's disease, three inflammatory diseases affecting distinct organs, was identified by combining evidence from linkage and GWAS data [75]. Recently antagonistic pleiotropic effects of genetic variants were evidenced conferring risk for one disease, diabetes type 1 , and protection for another disease, inflammatory bowel disease [76].

\section{Methodological challenge of data mining and of complex systems analysis}

The research community is facing unprecedented statistical, data mining and analytical challenges as the next steps ahead are complex interaction studies of genes, other omics markers, lifestyle, and environment on the phenome. Standard statistical approaches using linear causal relationships have shown to be limited for reproducible association studies on complex phenotypes as well as for two-way interaction analyses. Researchers will need to adapt their current methods by implementing approaches that reflect more closely the dynamics of adaptive biologic systems by taking non-linear and non-proportional relationships into account. Methods of complex system science and chaos theory have been applied to various biologic systems [77] and have been proposed to be applied to human health behavioral changes for public health prevention aims [78]. Fractal dynamics in physiology have shown to be relevant 
Table 2 Risk factors of NCDs and aging

\begin{tabular}{|c|c|c|c|}
\hline Risk factor studied & Disease or trait & Acclerated aging and impaired function & Reference \\
\hline \multirow[t]{7}{*}{ Smoking } & Humoral immunity & Immune system aging & [48] \\
\hline & Inflammatory response & Immune system aging & [53] \\
\hline & Heart rate variabiltiy & Autnomous nervous system aging & [54] \\
\hline & Alzheimer & Premature cognitive impairment, CNS aging & [55] \\
\hline & Atherosclerosis & Cardiovascular aging & [56] \\
\hline & Elastosis of the neck & Skin aging & [57] \\
\hline & Bone mineral density & Bone aging & [58] \\
\hline Obesity, BMI, high calorie intake, & Impaired immune response & Immune system aging & [59] \\
\hline Waist-hip ratio, skin-folds, & CD8 Tcell activation & Immune system aging & [59] \\
\hline \multirow[t]{6}{*}{ Body weight } & Lipodystrophy & Adipocyte aging & [60] \\
\hline & Heart rate variabiltiy & Autnomous nervous system aging & [61] \\
\hline & Alzheimer & Premature cognitive impairment, CNS aging & [55] \\
\hline & Atherosclerosis & Cardiovascular aging & [56] \\
\hline & Alopecia & Hair aging & [62] \\
\hline & Bone mineral density & Bone aging & [58] \\
\hline \multirow[t]{2}{*}{ Dyslipidemia } & Atherosclerosis & Cardiovascular aging & [56] \\
\hline & Alopecia & Hair aging & [62] \\
\hline \multirow[t]{2}{*}{ History of diabetes } & Alzheimer & Premature cognitive impairment, CNS aging & [55] \\
\hline & Bone mineral density & Bone aging & [58] \\
\hline Hypertension, & Alzheimer & Premature cognitive impairment, CNS aging & [55] \\
\hline \multirow[t]{3}{*}{ High resting pulse } & Atherosclerosis & Cardiovascular aging & [56] \\
\hline & Osteoporosis & Bone aging & [63] \\
\hline & Bone mineral density & Bone aging & [58] \\
\hline Other chronic diseases, & Immunosenescence & Immune system aging & [64] \\
\hline \multirow[t]{4}{*}{ Comorbidity } & Lipodystrophy & Adipocyte aging & [65] \\
\hline & Atherosclerosis & Cardiovascular aging & [56] \\
\hline & Sacropenia & Muscle aging & [66] \\
\hline & Osteoporosis & Bone aging & [63] \\
\hline \multirow[t]{2}{*}{ Medication intake } & Sacropenia & Muscle aging & [66] \\
\hline & Osteoporosis & Bone aging & [63] \\
\hline UV light/sun exposure & Alopecia & Hair aging & [62] \\
\hline \multirow[t]{2}{*}{ Low sun exposure } & Elastosis of the neck & Skin aging & [57] \\
\hline & Sacropenia & Muscle aging & [66] \\
\hline Health behaviours & Alzheimer & Premature cognitive impairment, CNS aging & [55] \\
\hline Low level of mental activity & Atherosclerosis & Cardiovascular aging & [56] \\
\hline \multirow[t]{2}{*}{ Physical inactivity } & Sacropenia & Muscle aging & [66] \\
\hline & Osteoporosis & Bone aging & [63] \\
\hline Depression & Atherosclerosis & Cardiovascular aging & [56] \\
\hline Poor diet & Sacropenia & Muscle aging & [66] \\
\hline Weight loss/no weight gain & Osteoporosis & Bone aging & [63] \\
\hline \multirow[t]{2}{*}{ Low education } & Alzheimer & Premature cognitive impairment, CNS aging & [55] \\
\hline & Atherosclerosis & Cardiovascular aging & [56] \\
\hline Psychosocial factors & Alzheimer & Premature cognitive impairment, CNS aging & [55] \\
\hline
\end{tabular}

Content of table is illustrative, not exhaustive. 
Table 3 Pleiotropic GWAS loci of NCDs

\begin{tabular}{|c|c|c|c|c|c|}
\hline Locus, gene & dbSNP ID & NCD entity associated with SNP & P-value & $\begin{array}{c}\text { Risk } \\
\text { allele frequency }\end{array}$ & PubMed ID \\
\hline \multicolumn{6}{|c|}{ Cancer linked NCDs cluster } \\
\hline \multirow[t]{9}{*}{ 5p15.33, TERT } & rs2736100 & Glioma & $2.00 \mathrm{E}-17$ & 0.49 & 19578367 \\
\hline & rs2736100 & Glioma & $1.00 \mathrm{E}-14$ & $N R$ & 21531791 \\
\hline & rs2736100 & Glioma & 7.00E-09 & NR & 21827660 \\
\hline & rs2736100 & Hematological and biochemical traits & $3.00 \mathrm{E}-08$ & 0.4 & 20139978 \\
\hline & rs2736100 & Idiopathic pulmonary fibrosis & $3.00 \mathrm{E}-08$ & 0.41 & 18835860 \\
\hline & rs2736100 & Lung adenocarcinoma & $2.00 \mathrm{E}-22$ & 0.39 & 20700438 \\
\hline & rs2736100 & Lung adenocarcinoma & $3.00 \mathrm{E}-11$ & 0.39 & 20871597 \\
\hline & rs2736100 & Lung cancer & $1.00 \mathrm{E}-27$ & 0.41 & 21725308 \\
\hline & rs2736100 & Testicular germ cell cancer & $8.00 \mathrm{E}-15$ & 0.49 & 20543847 \\
\hline \multirow[t]{5}{*}{ 5p15.33, TERT, CLPTM1L } & rs401681 & Bladder cancer & $5.00 \mathrm{E}-07$ & 0.54 & 20972438 \\
\hline & rs401681 & Lung cancer & 8.00E-09 & NR & 18978787 \\
\hline & rs401681 & Melanoma & $3.00 \mathrm{E}-08$ & 0.46 & 21983787 \\
\hline & rs401681 & Pancreatic cancer & 7.00E-07 & 0.45 & 20101243 \\
\hline & rs401681 & Serum prostate-specific antigen levels & $1.00 \mathrm{E}-10$ & 0.55 & 21160077 \\
\hline \multirow[t]{7}{*}{ 8q24.21, Intergenic } & rs6983267 & Colorectal cancer & $1.00 \mathrm{E}-14$ & 0.49 & 17618284 \\
\hline & rs6983267 & Colorectal cancer & $7.00 \mathrm{E}-11$ & 0.48 & 18372905 \\
\hline & rs6983267 & Colorectal cancer & $2.00 \mathrm{E}-08$ & 0.34 & 21242260 \\
\hline & rs6983267 & Prostate cancer & $9.00 \mathrm{E}-13$ & 0.5 & 17401363 \\
\hline & rs6983267 & Prostate cancer & $9.00 \mathrm{E}-13$ & 0.49 & 18264097 \\
\hline & rs6983267 & Prostate cancer & $7.00 \mathrm{E}-12$ & 0.53 & 18264096 \\
\hline & rs6983267 & Prostate cancer & $9.00 \mathrm{E}-06$ & NR & 21743057 \\
\hline \multirow[t]{2}{*}{ 9p21.3, CDKN2A, CDKN2B } & rs4977756 & Glaucoma & $1.00 \mathrm{E}-14$ & 0.6 & 21532571 \\
\hline & rs4977756 & Glioma & $7.00 \mathrm{E}-15$ & 0.6 & 19578367 \\
\hline \multicolumn{6}{|c|}{ Inflammatory trait linked NCDs cluster } \\
\hline \multirow[t]{11}{*}{ 1p31.3, IL23R } & rs11209026 & Ankylosing spondylitis & $2.00 \mathrm{E}-17$ & 0.93 & 21743469 \\
\hline & rs11209026 & Ankylosing spondylitis & $9.00 \mathrm{E}-14$ & 0.94 & 20062062 \\
\hline & rs11209026 & Crohn's disease & $1.00 \mathrm{E}-64$ & 0.93 & 21102463 \\
\hline & rs11209026 & Crohn's disease & $4.00 \mathrm{E}-21$ & NR & 22293688 \\
\hline & rs11209026 & Crohn's disease & $2.00 \mathrm{E}-18$ & 0.92 & 17447842 \\
\hline & rs11209026 & Inflammatory bowel disease & $4.00 \mathrm{E}-11$ & 0.93 & 17068223 \\
\hline & rs11209026 & Inflammatory bowel disease & 7.00E-11 & 0.94 & 18758464 \\
\hline & rs11209026 & Psoriasis & 7.00E-07 & NR & 20953190 \\
\hline & rs11209026 & Ulcerative colitis & $5.00 \mathrm{E}-28$ & 0.94 & 21297633 \\
\hline & rs11209026 & Ulcerative colitis & $3.00 \mathrm{E}-10$ & NR & 19915572 \\
\hline & rs11209026 & Ulcerative colitis & $1.00 \mathrm{E}-08$ & 0.93 & 19122664 \\
\hline \multirow[t]{7}{*}{ 1p13.2, PTPN22 } & rs2476601 & Crohn's disease & $1.00 \mathrm{E}-08$ & 0.9 & 18587394 \\
\hline & rs2476601 & Rheumatoid arthritis & $9.00 \mathrm{E}-74$ & 0.1 & 20453842 \\
\hline & rs2476601 & Rheumatoid arthritis & $2.00 \mathrm{E}-21$ & NR & 19503088 \\
\hline & rs2476601 & Rheumatoid arthritis & $2.00 \mathrm{E}-11$ & 0.1 & 17804836 \\
\hline & rs2476601 & Type 1 diabetes & $9.00 \mathrm{E}-85$ & NR & 19430480 \\
\hline & rs2476601 & Type 1 diabetes & $2.00 \mathrm{E}-80$ & 0.09 & 17554260 \\
\hline & rs2476601 & Type 1 diabetes & $1.00 \mathrm{E}-07$ & 0.09 & 17632545 \\
\hline
\end{tabular}


Table 3 Pleiotropic GWAS loci of NCDs (Continued)

\begin{tabular}{|c|c|c|c|c|c|}
\hline & rs2476601 & Type 1 diabetes autoantibodies & $2.00 \mathrm{E}-111$ & $N R$ & 21829393 \\
\hline & rs2476601 & Vitiligo & $1.00 \mathrm{E}-07$ & 0.1 & 20410501 \\
\hline \multirow[t]{9}{*}{ 7q32.1, IRF5,TNPO3 } & rs10488631 & Primary biliary cirrhosis & $3.00 \mathrm{E}-10$ & 0.11 & 20639880 \\
\hline & rs10488631 & Primary biliary cirrhosis & 2.00E-07 & $N R$ & 19458352 \\
\hline & rs10488631 & Rheumatoid arthritis & 4.00E-11 & 0.11 & 20453842 \\
\hline & rs10488631 & Systemic lupus erythematosus & 7.00E-18 & 0.11 & 21408207 \\
\hline & rs10488631 & Systemic lupus erythematosus & $2.00 \mathrm{E}-11$ & 0.12 & 18204098 \\
\hline & rs10488631 & Systemic sclerosis & $2.00 \mathrm{E}-13$ & $N R$ & 20383147 \\
\hline & rs10488631 & Systemic sclerosis & $2.00 \mathrm{E}-10$ & $N R$ & 21779181 \\
\hline & rs10488631 & Systemic sclerosis & $2.00 \mathrm{E}-07$ & $N R$ & 21779181 \\
\hline & rs10488631 & Systemic sclerosis & 4.00E-07 & 0.09 & 21750679 \\
\hline \multirow[t]{6}{*}{ 18p11.21, PTPN2 } & rs2542151 & Crohn's disease & $5.00 \mathrm{E}-17$ & 0.15 & 18587394 \\
\hline & rs 2542151 & Crohn's disease & $3.00 \mathrm{E}-08$ & 0.18 & 17554261 \\
\hline & rs2542151 & Crohn's disease & 2.00E-07 & 0.16 & 17554300 \\
\hline & rs2542151 & Type 1 diabetes & $1.00 \mathrm{E}-14$ & 0.16 & 17554260 \\
\hline & rs2542151 & Type 1 diabetes & $9.00 \mathrm{E}-08$ & $N R$ & 18978792 \\
\hline & rs2542151 & Type 1 diabetes autoantibodies & 4.00E-13 & $N R$ & 21829393 \\
\hline \multirow[t]{3}{*}{ 18p11.21, PTPN2 } & rs1893217 & Celiac disease & $3.00 \mathrm{E}-10$ & 0.17 & 20190752 \\
\hline & rs1893217 & Celiac disease and Rheumatoid arthritis & $5.00 \mathrm{E}-12$ & $N R$ & 21383967 \\
\hline & rs1893217 & Type 1 diabetes & 4.00E-15 & $N R$ & 19430480 \\
\hline \multicolumn{6}{|c|}{ Cardiovascular trait linked NCDs cluster } \\
\hline \multirow[t]{14}{*}{ 2p23.3, GCKR } & rs1260326 & Cardiovascular disease risk factors & $2.00 \mathrm{E}-08$ & 0.4 & 21943158 \\
\hline & rs1260326 & Cholesterol, total & $7.00 \mathrm{E}-27$ & 0.41 & 20686565 \\
\hline & rs1260326 & Chronic kidney disease & $3.00 \mathrm{E}-14$ & 0.41 & 20383146 \\
\hline & rs1260326 & C-reactive protein & $5.00 \mathrm{E}-40$ & $N R$ & 21300955 \\
\hline & rs1260326 & Hematological and biochemical traits & 4.00E-09 & 0.44 & 20139978 \\
\hline & rs1260326 & Hypertriglyceridemia & 7.00E-09 & 0.41 & 20657596 \\
\hline & rs1260326 & Liver enzyme levels (gamma-glutamyl transferase) & 4.00E-13 & 0.38 & 22001757 \\
\hline & rs1260326 & Metabolic traits & 4.00E-10 & 0.35 & 19060910 \\
\hline & rs1260326 & Platelet counts & $9.00 \mathrm{E}-10$ & $N R$ & 22139419 \\
\hline & rs1260326 & Serum metabolites & $3.00 \mathrm{E}-18$ & $N R$ & 22286219 \\
\hline & rs1260326 & Triglycerides & $6.00 \mathrm{E}-133$ & 0.41 & 20686565 \\
\hline & rs1260326 & Triglycerides & $2.00 \mathrm{E}-31$ & 0.45 & 19060906 \\
\hline & rs1260326 & Two-hour glucose challenge & $3.00 \mathrm{E}-10$ & $N R$ & 20081857 \\
\hline & rs1260326 & Waist circumference and related phenotypes & 4.00E-08 & $N R$ & 18454146 \\
\hline \multirow[t]{8}{*}{ 11q12.2, FADS1, FADS2 } & rs 174547 & HDL cholesterol & $2.00 \mathrm{E}-12$ & 0.33 & 19060906 \\
\hline & rs 174547 & Lipid metabolism phenotypes & $8.00 \mathrm{E}-262$ & $N R$ & 22286219 \\
\hline & rs 174547 & Metabolic traits & $9.00 \mathrm{E}-116$ & 0.32 & 21886157 \\
\hline & rs 174547 & Phospholipid levels (plasma) & 4.00E-154 & $N R$ & 21829377 \\
\hline & rs 174547 & Phospholipid levels (plasma) & $3.00 \mathrm{E}-64$ & $N R$ & 21829377 \\
\hline & rs174547 & Resting heart rate & 2.00E-09 & 0.33 & 20639392 \\
\hline & rs 174547 & Serum metabolites & 7.00E-179 & 0.3 & 20037589 \\
\hline & rs 174547 & Triglycerides & $2.00 \mathrm{E}-14$ & 0.33 & 19060906 \\
\hline \multirow[t]{2}{*}{ 11q14.3, MTNR1B } & rs1387153 & Fasting plasma glucose & $2.00 \mathrm{E}-36$ & 0.29 & 19060909 \\
\hline & rs1387153 & Glycated hemoglobin levels & 4.00E-11 & 0.28 & 20858683 \\
\hline
\end{tabular}


Table 3 Pleiotropic GWAS loci of NCDs (Continued)

\begin{tabular}{|c|c|c|c|c|c|}
\hline & rs1387153 & Metabolic syndrome (bivariate traits) & 2.00E-09 & NR & 21386085 \\
\hline & rs1387153 & Metabolic syndrome (bivariate traits) & 8.00E-09 & NR & 21386085 \\
\hline & rs1387153 & Type 2 diabetes & $8.00 \mathrm{E}-15$ & NR & 20581827 \\
\hline \multirow[t]{7}{*}{ 12q24.12, ALDH2, BRAP } & rs671 & Coronary heart disease & $2.00 \mathrm{E}-34$ & 0.23 & 21971053 \\
\hline & rs671 & Drinking behavior & 4.00E-211 & 0.75 & 21372407 \\
\hline & rs671 & Esophageal cancer & $3.00 \mathrm{E}-24$ & NR & 19698717 \\
\hline & rs671 & Hematological and biochemical traits & 7.00E-10 & 0.26 & 20139978 \\
\hline & rs671 & Hematological and biochemical traits & 5.00E-09 & 0.26 & 20139978 \\
\hline & rs671 & Intracranial aneurysm & $3.00 \mathrm{E}-06$ & 0.75 & 22286173 \\
\hline & rs671 & Triglycerides & 2.00E-06 & NR & 22171074 \\
\hline \multirow[t]{13}{*}{ 16q13, CETP } & rs3764261 & Age-related macular degeneration & 7.00E-09 & 0.33 & 21665990 \\
\hline & rs3764261 & Age-related macular degeneration & 7.00E-07 & 0.32 & 20385819 \\
\hline & rs3764261 & Cholesterol, total & 7.00E-14 & 0.32 & 20686565 \\
\hline & rs3764261 & HDL cholesterol & $2.00 \mathrm{E}-57$ & 0.31 & 18193043 \\
\hline & rs3764261 & HDL cholesterol & 7.00E-29 & 0.28 & 19060910 \\
\hline & rs3764261 & HDL cholesterol & $3.00 \mathrm{E}-12$ & 0.2 & 19359809 \\
\hline & rs3764261 & HDL cholesterol & $7 E-380$ & 0.32 & 20686565 \\
\hline & rs3764261 & LDL cholesterol & $9.00 \mathrm{E}-13$ & 0.32 & 20686565 \\
\hline & rs3764261 & Lipid metabolism phenotypes & $1.00 \mathrm{E}-36$ & NR & 22286219 \\
\hline & rs3764261 & Metabolic syndrome & $1.00 \mathrm{E}-48$ & 0.36 & 20694148 \\
\hline & rs3764261 & Metabolic syndrome & $3.00 \mathrm{E}-13$ & NR & 21386085 \\
\hline & rs3764261 & Triglycerides & $1.00 \mathrm{E}-12$ & 0.45 & 20686565 \\
\hline & rs3764261 & Waist circumference & $1.00 \mathrm{E}-27$ & NR & 18454146 \\
\hline \multirow[t]{8}{*}{ 19p13.2, LDLR } & rs6511720 & Cardiovascular disease risk factors & 5.00E-11 & 0.11 & 21943158 \\
\hline & rs6511720 & Carotid intima media thickness & $1.00 \mathrm{E}-07$ & NR & 21909108 \\
\hline & rs6511720 & Cholesterol, total & 7.00E-97 & 0.11 & 20686565 \\
\hline & rs6511720 & LDL cholesterol & 4.00E-117 & 0.11 & 20686565 \\
\hline & rs6511720 & LDL cholesterol & $2.00 \mathrm{E}-51$ & 0.1 & 18193044 \\
\hline & rs6511720 & LDL cholesterol & $2.00 \mathrm{E}-26$ & 0.1 & 19060906 \\
\hline & rs6511720 & LDL cholesterol & 4.00E-26 & 0.9 & 18193043 \\
\hline & rs6511720 & Lp-PLA2 activity and mass & $3.00 \mathrm{E}-11$ & 0.1 & 22003152 \\
\hline \multirow[t]{14}{*}{ 19q13.32, APOE, APOC1 } & rs4420638 & Alzheimer's disease & $2.00 \mathrm{E}-44$ & NR & 17998437 \\
\hline & rs4420638 & Alzheimer's disease & 1.00E-39 & NR & 17975299 \\
\hline & rs4420638 & Alzheimer's disease (age of onset) & $1.00 \mathrm{E}-12$ & NR & 22005931 \\
\hline & rs4420638 & Alzheimer's disease (late onset) & $1.00 \mathrm{E}-39$ & NR & 17474819 \\
\hline & rs4420638 & Cholesterol, total & $5.00 \mathrm{E}-111$ & 0.17 & 20686565 \\
\hline & rs4420638 & Cognitive decline & 4.00E-27 & $N R$ & 22054870 \\
\hline & rs4420638 & C-reactive protein & $9.00 \mathrm{E}-139$ & NR & 21300955 \\
\hline & rs4420638 & C-reactive protein & $5.00 \mathrm{E}-27$ & NR & 19567438 \\
\hline & rs4420638 & C-reactive protein & $3.00 \mathrm{E}-07$ & 0.9 & 21196492 \\
\hline & rs4420638 & HDL cholesterol & 4.00E-21 & 0.17 & 20686565 \\
\hline & rs4420638 & LDL cholesterol & $9.00 \mathrm{E}-147$ & 0.17 & 20686565 \\
\hline & rs4420638 & LDL cholesterol & $1.00 \mathrm{E}-60$ & 0.2 & 18193044 \\
\hline & rs4420638 & LDL cholesterol & $3.00 \mathrm{E}-43$ & 0.18 & 18193043 \\
\hline & rs4420638 & LDL cholesterol & $2.00 \mathrm{E}-40$ & 0.18 & 20864672 \\
\hline
\end{tabular}


Table 3 Pleiotropic GWAS loci of NCDs (Continued)

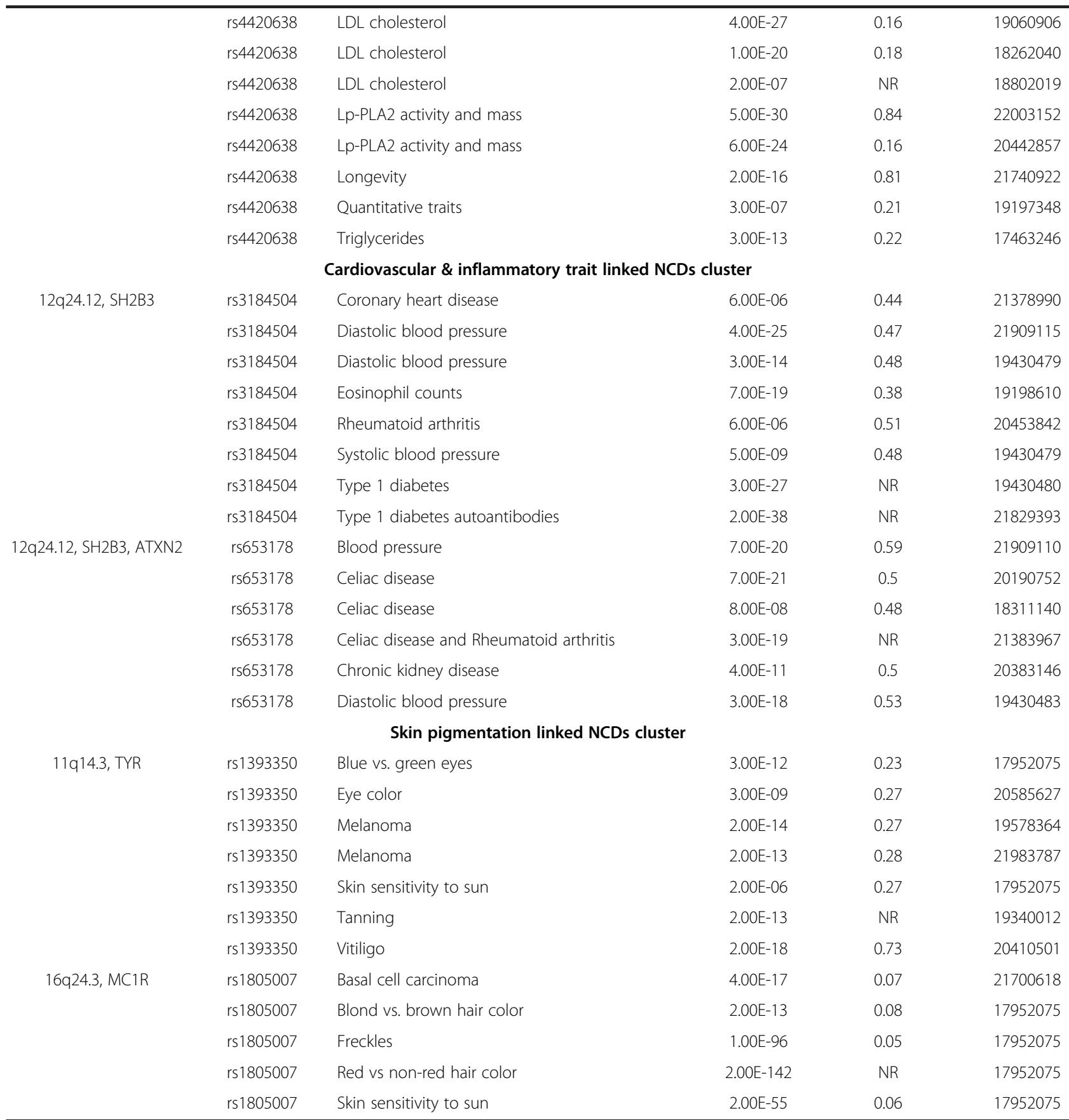

A selection of GWAS identified pleiotropic SNPs implicated in more than one NCD entity are presented here. For a more complete list of pleiotropic loci see Additional file 1. Data has been downloaded (09 March 2012) from the online catalogue of published GWAS available at www.genome.gov/gwastudies. NR, not reported.

Lp-PLA2, lipoprotein-associated Phospholipase A2.

LDLR, Low density lipoprotein receptor.

$H D L$, High density lipoprotein.

LDLR, Low density lipoprotein.

to disease and aging [79], to biologic signals in general [80] and chaotic motifs have been investigated in dynamic behavior of gene regulatory networks [81]. To date we have only started to investigate disease clusters and pleiotropic risk effects in a systematic manner $[82,83]$. Formal analytical concepts of disease similarities and shared gene networks have been proposed to guide future research for the identification of molecular evidence of comorbidities 
[84]. Recent novel data mining approaches to combine GWAS findings and phenome data have been proposed to achieve NCD disease gene discovery, phenotype classification [41] and phenome-wide association studies [85] or to improve disease diagnostic procedures $[27,86]$. Other bioinfomatic approaches combining animal model data of human disease and mammalian phenotype ontologies databases seem to suggest that germline genetic variation might underlie the heterogeneity of comorbidities $[87,88]$.

\section{Summary}

In the present report, we covered a wide range of aspects of importance to NCD research, including establishments and maintenance of large and systematic biobank cohorts from all parts of the world; implementation of broad and detailed phenotyping, as well as broad and detailed risk factor assessment, including aging characteristics; development of novel analytical methods for systemic analysis, addressing networks of diseases, or of personal and environmental risk factors, as well application of agnostic genomic analysis methods. In fact, to meet current and future public health challenges and to improve efficacy of prevention at the individual as well as at the population level, we need answers to the following questions [89-92]: Which are major pathophysiologic pathways mediating the clustering of NCDs? To what degree are biological mechanisms shared between NCDs and normal aging? Do modifiable NCD risk factors act through common mechanisms? Can persons susceptible to common NCD risk patterns and comorbidities be identified?

To address this type of questions with data providing adequate statistical power and using hypothesis driven and explorative as well as agnostic approaches, establishment and maintenance of carefully designed large and comprehensive population-based cohorts with prospective collection of biological samples are a key requirement. Efforts must be further intensified to collaborate across cohorts from different geographic regions in a harmonized fashion, a process already started with remarkable success in P3G [93]. Harmonized and exhaustive phenotype collection is a particular challenge and novel instruments as developed for standardized assessment of multiple chronic diseases etiology [94] must be implemented. The quality management of a sustainable long-term biobank importantly comprises next to legislative, ethical and financial aspects also guaranteed safety of samples, temperature monitoring, traceability and parsimonious use of sample aliquots. Quality management of biological sample collection is particularly important for cohort studies with multi-centric design.

Given that biobank cohorts serve to increase the wellbeing of future generations by indirectly promoting biomedical knowledge and public health, these activities require the development of normative procedures and defined governance $[95,96]$. There are still issues left to be resolved, such as establishing large biobanks for investigation of future research questions conflicts with the well accepted and widely implemented personal informed consent [97]. In the light of biobanking's interest for present and future society, it might be considered a great good [95] and according discussions for a possibility of general non-personalized consent in politics and public are needed. This debate paper aimed to highlight the potential of biobank cohort research for complex disease etiology, a field of research that will allow improving health of populations as well as informing individuals on quality-of life increasing health decisions.

\section{Additional files}

Additional file 1: Evidence for pleiotropic loci identified by GWAS.

Additional file 2: Evidence for non-random clustering of NCD-linked traits and specific pleiotropic GWAS-identified SNPs.

\section{Competing interests}

The authors declare that they have no competing interests.

\section{Authors' contributions}

Both authors made substantial contributions to the conception and design of the paper. NPH is the principal investigator of the SAPALDIA biobank cohort. MI contributed significantly to the set-up of the SAPALDIA biobank and summarized current database and literature findings. Both authors have been involved in interpreting the data, as well as drafting and critically revising the debate manuscript. $\mathrm{MI}$ and $\mathrm{NPH}$ have given final approval of the version to be published.

Received: 27 July 2012 Accepted: 25 September 2013

Published: 25 November 2013

\section{References}

1. Murray CJ, Vos T, Lozano R, Naghavi M, Flaxman AD, Michaud C, Ezzati M, Shibuya K, Salomon JA, Abdalla S, et al: Disability-adjusted life years (DALYs) for 291 diseases and injuries in 21 regions, 1990-2010: a systematic analysis for the global burden of disease study 2010. Lancet 2012, 380(9859):2197-2223.

2. Vaught J, Lockhart NC: The evolution of biobanking best practices. Clin Chim Acta 2012, 413(19-20):1569-1575.

3. Myles R, Massett HA, Comey G, Atkinson N, Allsop D, Compton C: Stakeholder research on biospecimen needs and reactions to the development of a national cancer human biobank by the National Cancer Institute. J Natl Cancer Inst Monogr 2011, 2011(42):16-23.

4. Collins R: What makes UK Biobank special? Lancet 2012, 379(9822):1173-1174.

5. Li L, Guo Y, Chen Z, Chen J, Peto R: Epidemiology and the control of disease in China, with emphasis on the Chinese Biobank Study. Public Health 2012, 126(3):210-213.

6. Manolio TA, Weis BK, Cowie CC, Hoover RN, Hudson K, Kramer BS, Berg C, Collins R, Ewart W, Gaziano JM, et al: New models for large prospective studies: is there a better way? Am J Epidemiol 2012, 175(9):859-866.

7. Nair H, Shu XO, Volmink J, Romieu I, Spiegelman D: Cohort studies around the world: methodologies, research questions and integration to address the emerging global epidemic of chronic diseases. Public Health 2012, 126(3):202-205.

8. Murray CJ, Frenk J, Piot P, Mundel T: GBD 2.0: a continuously updated global resource. Lancet 2013, 382(9886):9-11.

9. Remais JV, Zeng G, Li G, Tian L, Engelgau MM: Convergence of non-communicable and infectious diseases in low- and middle-income countries. Int J Epidemiol 2013, 42(1):221-227. 
10. Probst-Hensch N, Kunzli N: Preventing noncommunicable diseases-beyond lifestyle. Epidemiology 2012, 23(2):181-183.

11. Ebrahim S, Pearce N, Smeeth L, Casas JP, Jaffar S, Piot P: Tackling non-communicable diseases in low- and middle-income countries: is the evidence from high-income countries all we need? PLOS Med 2013, 10(1):e1001377

12. Genomes Project $C$, Abecasis GR, Auton A, Brooks LD, DePristo MA, Durbin RM, Handsaker RE, Kang HM, Marth GT, McVean GA: An integrated map of genetic variation from 1,092 human genomes. Nature 2012, 491(7422):56-65.

13. Teo K, Lear S, Islam S, Mony P, Dehghan M, Li W, Rosengren A, Lopez-Jaramillo $P$, Diaz R, Oliveira $G$, et al: Prevalence of a healthy lifestyle among individuals with cardiovascular disease in high-, middle- and low-income countries: The Prospective Urban Rural Epidemiology (PURE) study. JAMA 2013, 309(15):1613-1621.

14. Elwell-Sutton TM, Jiang CQ, Zhang WS, Cheng KK, Lam TH, Leung GM, Schooling CM: Inequality and inequity in access to health care and treatment for chronic conditions in China: the Guangzhou Biobank cohort study. Health Policy Plan 2012, 28:467.

15. Rottingen JA, Regmi S, Eide M, Young AJ, Viergever RF, Ardal C, Guzman J, Edwards D, Matlin SA, Terry RF: Mapping of available health research and development data: what's there, what's missing, and what role is there for a global observatory? Lancet 2013, 382(9900):1286-1307.

16. Moffatt MF, Gut IG, Demenais F, Strachan DP, Bouzigon E, Heath S, von Mutius E, Farrall M, Lathrop M, Cookson WO: A large-scale, consortium-based genomewide association study of asthma. N Engl J Med 2010, 363(13):1211-1221.

17. Moffatt MF, Kabesch M, Liang L, Dixon AL, Strachan D, Heath S, Depner M, von Berg A, Bufe A, Rietschel E, et al: Genetic variants regulating ORMDL3 expression contribute to the risk of childhood asthma. Nature 2007, 448(7152):470-473.

18. Siroux V, Basagana X, Boudier A, Pin I, Garcia-Aymerich J, Vesin A, Slama R, Jarvis D, Anto JM, Kauffmann F, et al: Identifying adult asthma phenotypes using a clustering approach. Eur Respir J 2011, 38(2):310-317.

19. Ioannidis JP, Trikalinos TA, Khoury MJ: Implications of small effect sizes of individual genetic variants on the design and interpretation of genetic association studies of complex diseases. Am J Epidemiol 2006, 164(7):609-614.

20. Maher B: Personal genomes: the case of the missing heritability. Nature 2008, 456(7218):18-21.

21. Manolio TA, Collins FS, Cox NJ, Goldstein DB, Hindorff LA, Hunter DJ, McCarthy MI, Ramos EM, Cardon LR, Chakravarti A, et al: Finding the missing heritability of complex diseases. Nature 2009, 461(7265):747-753.

22. Freimer N, Sabatti C: The human phenome project. Nat Genet 2003, 34(1):15-21.

23. Oetting WS, Robinson PN, Greenblatt MS, Cotton RG, Beck T, Carey JC, Doelken SC, Girdea M, Groza T, Hamilton CM, et al: Getting ready for the human phenome project: the 2012 forum of the human variome project. Hum Mutat 2013, 34(4):661-666.

24. Potash JB, Toolan J, Steele J, Miller EB, Pearl J, Zandi PP, Schulze TG, Kassem L, Simpson SG, Lopez V, et al: The bipolar disorder phenome database: a resource for genetic studies. Am J Psychiatry 2007, 164(8):1229-1237.

25. Nesbitt G, McKenna K, Mays V, Carpenter A, Miller K, Williams M: The Epilepsy Phenome/Genome Project (EPGP) informatics platform. Int J Med Inform 2012, 82:248

26. Maddatu TP, Grubb SC, Bult CJ, Bogue MA: Mouse Phenome Database (MPD). Nucleic Acids Res 2012, 40(Database issue):D887-D894.

27. Piran S, Liu P, Morales A, Hershberger RE: Where genome meets phenome: rationale for integrating genetic and protein biomarkers in the diagnosis and management of dilated cardiomyopathy and heart failure. J Am Coll Cardiol 2012, 60(4):283-289

28. Eppsteiner RW, Shearer AE, Hildebrand MS, Taylor KR, Deluca AP, Scherer S, Huygen P, Scheetz TE, Braun TA, Casavant TL, et al: Using the phenome and genome to improve genetic diagnosis for deafness. Otolaryngol Head Neck Surg 2012, 147(5):975-977.

29. Ritchie MD, Denny JC, Zuvich RL, Crawford DC, Schildcrout JS, Bastarache L Ramirez AH, Mosley JD, Pulley JM, Basford MA, et al: Genome- and phenome-wide analyses of cardiac conduction identifies markers of arrhythmia risk. Circulation 2013, 127(13):1377-1385.

30. Groza T, Hunter J, Zankl A: Decomposing phenotype descriptions for the human skeletal phenome. Biomed Inform Insights 2013, 6:1-14.
31. Warner $\mathrm{L}$, Alterovitz G: Phenome based analysis as a means for discovering context dependent clinical reference ranges. AMIA Symp 2012, 2012:1441-1449.

32. Pathak J, Kiefer RC, Bielinski SJ, Chute CG: Mining the human phenome using semantic web technologies: a case study for type 2 Diabetes. AMIA Symp 2012, 2012:699-708.

33. Pathak J, Kiefer RC, Bielinski SJ, Chute CG: Applying semantic web technologies for phenome-wide scan using an electronic health record linked Biobank. J Biomed Semantics 2012, 3(1):10.

34. Goh Kl, Cusick ME, Valle D, Childs B, Vidal M, Barabasi AL: The human disease network. Proc Natl Acad Sci U S A 2007, 104(21):8685-8690.

35. Barabasi AL, Gulbahce N, Loscalzo J: Network medicine: a network-based approach to human disease. Nat Rev Genet 2011, 12(1):56-68.

36. Garcia-Olmos L, Salvador CH, Alberquilla A, Lora D, Carmona M, Garcia-Sagredo P, Pascual M, Munoz A, Monteagudo JL, Garcia-Lopez F: Comorbidity patterns in patients with chronic diseases in general practice. PLoS One 2012, 7(2):e32141.

37. Marengoni A, Angleman S, Melis R, Mangialasche F, Karp A, Garmen A Meinow B, Fratiglioni L: Aging with multimorbidity: a systematic review of the literature. Ageing Res Rev 2011, 10(4):430-439.

38. Liu YI, Wise PH, Butte AJ: The "etiome": identification and clustering of human disease etiological factors. BMC Bioinforma 2009, 10(Suppl 2):S14.

39. Rzhetsky A, Wajngurt D, Park N, Zheng T: Probing genetic overlap among complex human phenotypes. Proc Natl Acad Sci U S A 2007, 104 (28):11694-11699.

40. Hidalgo CA, Blumm N, Barabasi AL, Christakis NA: A dynamic network approach for the study of human phenotypes. PLoS Comput Biol 2009, 5(4):e1000353.

41. Hwang T, Atluri G, Xie M, Dey S, Hong C, Kumar V, Kuang R: Co-clustering phenome-genome for phenotype classification and disease gene discovery. Nucleic Acids Res 2012, 40(19):e146.

42. Jain $P$, Vig S, Datta M, Jindel D, Mathur AK, Mathur SK, Sharma A: Systems biology approach reveals genome to phenome correlation in type 2 diabetes. Plos One 2013, 8(1):e53522.

43. Hebbring SJ, Schrodi SJ, Ye Z, Zhou Z, Page D, Brilliant MH: A PheWAS approach in studying HLA-DRB1*1501. Genes Immun 2013, 14(3):187-191.

44. Wild CP: Complementing the genome with an "exposome": the outstanding challenge of environmental exposure measurement in molecular epidemiology. Cancer Epidemiol Biomarkers Prev 2005, 14(8):1847-1850.

45. Rappaport SM, Smith MT: Epidemiology. environment and disease risks. Science 2010, 330(6003):460-461.

46. Callaway E: Daily dose of toxics to be tracked. Nature 2012, 491(7426):647

47. MacNee W: Accelerated lung aging: a novel pathogenic mechanism of chronic obstructive pulmonary disease (COPD). Biochem Soc Trans 2009, 37(Pt 4):819-823.

48. Edwards D: Immunological effects of tobacco smoking in "healthy" smokers. COPD 2009, 6(1):48-58.

49. Leung WC, Harvey I: Is skin ageing in the elderly caused by sun exposure or smoking? Br J Dermatol 2002, 147(6):1187-1191.

50. Bruce-Keller AJ, Keller JN, Morrison CD: Obesity and vulnerability of the CNS. Biochim Biophys Acta 2009, 1792(5):395-400.

51. Monickaraj F, Aravind S, Gokulakrishnan K, Sathishkumar C, Prabu P, Prabu D, Mohan V, Balasubramanyam M: Accelerated aging as evidenced by increased telomere shortening and mitochondrial DNA depletion in patients with type 2 diabete. Mol Cell Biochem 2012, 365(1-2):343-350.

52. Tzanetakou IP, Katsilambros NL, Benetos A, Mikhailidis DP: Perrea DN: "Is obesity linked to aging?" Adipose tissue and the role of telomeres. Ageing Res Rev 2012, 11(2):220-229.

53. Apatzidou DA, Riggio MP, Kinane DF: Impact of smoking on the clinical, microbiological and immunological parameters of adult patients with periodontitis. J Clin Periodontol 2005, 32(9):973-983.

54. Dinas PC, Koutedakis Y, Flouris AD: Effects of active and passive tobacco cigarette smoking on heart rate variability. Int J Cardio/ 2011, 163:109.

55. Barnes DE, Yaffe K: The projected effect of risk factor reduction on Alzheimer's disease prevalence. Lancet Neurol 2011, 10(9):819-828.

56. Kucharska-Newton AM, Couper DJ, Pankow JS, Prineas RJ, Rea TD, Sotoodehnia N, Chakravarti A, Folsom AR, Siscovick DS, Rosamond WD: Hemostasis, inflammation, and fatal and nonfatal coronary heart disease: long-term follow-up of the atherosclerosis risk in communities (ARIC) cohort. Arterioscler Thromb Vasc Biol 2009, 29(12):2182-2190. 
57. Green AC, Hughes MC, McBride P, Fourtanier A: Factors associated with premature skin aging (photoaging) before the age of 55: a population-based study. Dermatology 2011, 222(1):74-80.

58. Khoo CC, Woo J, Leung PC, Kwok A, Kwok T: Determinants of bone mineral density in older postmenopausal Chinese women. Climacteric 2011, 14(3):378-383.

59. Sheridan PA, Paich HA, Handy J, Karlsson EA, Hudgens MG, Sammon AB, Holland LA, Weir S, Noah TL, Beck MA: Obesity is associated with impaired immune response to influenza vaccination in humans. Int J Obes 2011, 36:1072-1077

60. Fardet L, Cabane J, Lebbe C, Morel P, Flahault A: Incidence and risk factors for corticosteroid-induced lipodystrophy: a prospective study. J Am Acad Dermatol 2007, 57(4):604-609.

61. Latchman PL, Mathur M, Bartels MN, Axtell RS, De Meersman RE: Impaired autonomic function in normotensive obese children. Clin Auton Res 2011, 21(5):319-323.

62. $\mathrm{Su} \mathrm{LH}$, Chen $\mathrm{HH}$ : Androgenetic alopecia in policemen: higher prevalence and different risk factors relative to the general population (KCIS no. 23). Arch Dermatol Res 2011, 303(10):753-761.

63. Martinez Perez JA, Palacios S, Garcia FC, Perez M: Assessing osteoporosis risk factors in Spanish menopausal women. Gynecol Endocrinol 2011 27(10):807-813.

64. Mohan SV, Liao YJ, Kim JW, Goronzy JJ, Weyand CM: Giant cell arteritis: immune and vascular aging as disease risk factors. Arthritis Res Ther 2011, 13(4):231.

65. Garg A, Agarwal AK: Lipodystrophies: disorders of adipose tissue biology. Biochim Biophys Acta 2009, 1791(6):507-513.

66. Scott D, Blizzard L, Fell J, Jones G: The epidemiology of sarcopenia in community living older adults: what role does lifestyle play? J Cachexia Sarcopenia Muscle 2011, 2(3):125-134.

67. Arai $Y$, Takayama M, Abe $Y$, Hirose N: Adipokines and aging. J Atheroscler Thromb 2011, 18(7):545-550.

68. Podtelezhnikov AA, Tanis KQ, Nebozhyn M, Ray WJ, Stone DJ, Loboda AP: Molecular insights into the pathogenesis of Alzheimer's disease and its relationship to normal aging. PLOS One 2011, 6(12):e29610.

69. Zhang Z, Francisco EM, Holden JK, Dennis RG, Tommerdahl M: Somatosensory information processing in the aging population. Front Aging Neurosci 2011, 3:18

70. Jeck WR, Siebold AP, Sharpless NE: Review: a meta-analysis of GWAS and age-associated diseases. Aging cell 2012, 11(5):727-731.

71. Sivakumaran S, Agakov F, Theodoratou E, Prendergast JG, Zgaga L, Manolio T, Rudan I, McKeigue P, Wilson JF, Campbell H: Abundant pleiotropy in human complex diseases and traits. Am J Hum Genet 2011, 89(5):607-618.

72. Becker KG: The common variants/multiple disease hypothesis of common complex genetic disorders. Med Hypotheses 2004, 62(2):309-317.

73. Contois $\mathrm{JH}$, Anamani DE, Tsongalis GJ: The underlying molecular mechanism of apolipoprotein E polymorphism: relationships to lipid disorders, cardiovascular disease, and Alzheimer's disease. Clin Lab Med 1996, 16(1):105-123.

74. Gudmundsson J, Sulem P, Manolescu A, Amundadottir LT, Gudbjartsson D, Helgason A, Rafnar T, Bergthorsson JT, Agnarsson BA, Baker A, et al: Genome-wide association study identifies a second prostate cancer susceptibility variant at 8q24. Nat Genet 2007, 39(5):631-637.

75. Wolf N, Quaranta M, Prescott NJ, Allen M, Smith R, Burden AD, Worthington J, Griffiths CE, Mathew CG, Barker JN, et al: Psoriasis is associated with pleiotropic susceptibility loci identified in type II diabetes and Crohn disease. J Med Genet 2008, 45(2):114-116.

76. Wang K, Baldassano R, Zhang H, Qu HQ, Imielinski M, Kugathasan S, Annese V, Dubinsky M, Rotter Jl, Russell RK, et al: Comparative genetic analysis of inflammatory bowel disease and type 1 diabetes implicates multiple loci with opposite effects. Hum Mol Genet 2010, 19(10):2059-2067.

77. Goldberger AL: Giles f. Filley lecture. Complex systems. Proc Am Thorac Soc 2006, 3(6):467-471

78. Resnicow K, Page SE: Embracing chaos and complexity: a quantum change for public health. Am J Public Health 2008, 98(8):1382-1389.

79. Goldberger AL, Amaral LA, Hausdorff JM, Ivanov P, Peng CK, Stanley HE: Fractal dynamics in physiology: alterations with disease and aging. Proc Natl Acad Sci U S A 2002, 99(Suppl 1):2466-2472.

80. Peng CK, Yang AC, Goldberger AL: Statistical physics approach to categorize biologic signals: from heart rate dynamics to DNA sequences. Chaos 2007, 17(1):015115.
81. Zhang Z, Ye W, Qian Y, Zheng Z, Huang X, Hu G: Chaotic motifs in gene regulatory networks. PLoS One 2012, 7(7):e39355.

82. Kent JW Jr: Analysis of multiple phenotypes. Genet Epidemio/ 2009 33(Suppl 1):S33-S39.

83. Karasik D, Kiel DP: Evidence for pleiotropic factors in genetics of the musculoskeletal system. Bone 2010, 46(5):1226-1237.

84. Keller BJ, Eichinger F, Kretzler M: Formal concept analysis of disease similarity. AMIA Summits on Translational Science proceedings AMIA Summit on Translational Science 2012, 2012:42-51.

85. Pendergrass SA, Dudek S, Crawford DC, Ritchie MD: Visually integrating and exploring high throughput Phenome-Wide Association (PheWAS) results using PheWAS-View. BioData Min 2012, 5(1):5.

86. Kohler S, Doelken SC, Rath A, Ayme S, Robinson PN: Ontological phenotype standards for neurogenetics. Hum Mutat 2012, 33:1333-1339.

87. Oellrich A, Gkoutos GV, Hoehndorf R, Rebholz-Schuhmann D: Quantitative comparison of mapping methods between human and mammalian phenotype ontology. J Biomed Semantics 2012, 3(Suppl 2):S1.

88. Rebholz-Schuhmann D, Oellrich A, Hoehndorf R: Text-mining solutions for biomedical research: enabling integrative biology. Nat Rev Genet 2012, 13(12):829-839.

89. Probst-Hensch NM: Chronic age-related diseases share risk factors: do they share pathophysiological mechanisms and why does that matter? Swiss Med Wkly 2010, 140:W13072

90. Harvey AE, Lashinger LM, Hursting SD: The growing challenge of obesity and cancer: an inflammatory issue. Ann N Y Acad Sci 2011, 1229:45-52.

91. Aller MA, Arias N, Fuentes-Julian S, Blazquez-Martinez A, Argudo S, Miquel MP, Arias JL, Arias J: Coupling inflammation with evo-devo. Med Hypotheses 2012, 78(6):721-731.

92. Boyer JF, Bongard V, Cantagrel A, Jamard B, Gottenberg JE, Mariette X, Davignon JL, Ferrieres J, Ruidavets JB, Dallongeville J, et al: Link between traditional cardiovascular risk factors and inflammation in early arthritis patients. Arthritis Care Res (Hoboken) 2012, 64(6):872-880

93. Knoppers BM, Fortier I, Legault D, Burton P: The Public Population Project in Genomics (P3G): a proof of concept? Eur J Hum Genet 2008 , 16(6):664-665

94. Diederichs C, Berger K, Bartels DB: The measurement of multiple chronic diseases-a systematic review on existing multimorbidity indices. J Gerontol A Biol Sci Med Sci 2011, 66(3):301-311.

95. Cordell S: The biobank as an ethical subject. Health Care Anal 2011 19(3):282-294

96. Gottweis $\mathrm{H}$, Chen H, Starkbaum J: Biobanks and the phantom public Human genetics 2011, 130(3):433-440.

97. Holm S: Withdrawing from research: a rethink in the context of research biobanks. Health Care Anal 2011, 19(3):269-281.

doi:10.1186/1471-2458-13-1094

Cite this article as: Imboden and Probst-Hensch: Biobanking across the phenome - at the center of chronic disease research. BMC Public Health 2013 13:1094.

\section{Submit your next manuscript to BioMed Central and take full advantage of:}

- Convenient online submission

- Thorough peer review

- No space constraints or color figure charges

- Immediate publication on acceptance

- Inclusion in PubMed, CAS, Scopus and Google Scholar

- Research which is freely available for redistribution 